\title{
Synovial chondrosarcoma
}

\author{
Alessio Biazzo, Norberto Confalonieri \\ Orthopaedic Department, ASST Gaetano Pini-CTO, via Bignami 1, Milano, Italy \\ Contributions: (I) Conception and design: A Biazzo; (II) Administrative support: N Confalonieri; (III) Provision of study materials or patients: A \\ Biazzo; (IV) Collection and assembly of data: A Biazzo; (V) Data analysis and interpretation: A Biazzo; (VI) Manuscript writing: All authors; (VII) \\ Final approval of manuscript: All authors. \\ Correspondence to: Alessio Biazzo. Orthopaedic Department, ASST Gaetano Pini-CTO, via Bignami 1, Milano, Italy. Email: ale.biazzo@yahoo.it.
}

\begin{abstract}
Background: Synovial chondrosarcoma $(\mathrm{SCH})$ is a very rare tumor arising in the intra-articular cavity. In the majority of literature reports it is described as a malignant transformation of a pre-existing synovial chondromatosis (SC). We reported a systematic review of primary and secondary SCH described in the literature with the aim to recollect data from different case-reports and case-series, trying to summarize general aspects of this very rare disease.
\end{abstract}

Methods: We collected 42 abstracts in the form of case series and case reports, which reported 67 cases of SCH. Studies were taken into account only if they proved a histological diagnosis of SCH, either primary or secondary, with or without evidence of pre-existing SC.

Results: The average age of SCH was 56.9 years, with prevalence for male sex. The average time of malignant transformation was 11.2 years. The most affected joint was the knee (47.7\%), followed by hip (34.3\%) and ankle (5.9\%). SCH was described as de novo sarcoma only in 13 cases (19\%). Surgery ended up with amputation in $59.7 \%$ of cases. Local recurrence rate was $28.3 \%$.

Conclusions: We concluded that prognosis of SCH is worse than conventional one and we speculated this is due to the difficult site of the tumor (intraarticular), diagnostic delay and inappropriate previous treatments. We consider that a rapid deterioration of a SC or rapid recurrence after synoviectomy should be considered suspicious of malignant transformation and should be treated in a reference center.

Keywords: Synovial chondrosarcoma (SCH); malignant transformation; synovial chondromatosis (SC); synovial tumor

Submitted May 17, 2016. Accepted for publication May 24, 2016.

doi: $10.21037 /$ atm.2016.06.23

View this article at: http://dx.doi.org/10.21037/atm.2016.06.23

\section{Introduction}

Synovial chondrosarcoma (SCH) is a very rare type of chondrosarcoma (CHS) arising in the intraarticular cavity. The median age of patients is 50 years, with a slight prevalence in males (1). The most frequently affected joint is the knee, followed by hip, ankle, shoulder, elbow and wrist. $\mathrm{SCH}$ can be either primary or secondary to a pre-existing synovial chondromatosis (SC). In the majority of literature reports it is described as a malignant transformation of a pre-existing SC, but sporadically the occurrence of primary SCH has been observed $(2,3)$.

The recommended treatment for $\mathrm{SCH}$ is extra-articular resection with wide surgical margins or amputation when limb salvage is not feasible due to tumoral involvement of the neurovascular bundle (1).

Synoviectomy, with or without joint replacement, has been described to be successful in low-grade tumors (4). According to Campanacci et al. the prognosis of SCH is comparable to that of conventional CHS and depends on the histological grade of malignancy of the lesion (1). It seems important to perform an adequate surgical treatment with wide margins, in order to avoid local recurrences, which appeared to be a bad prognostic factor (2).

We reported a systematic review of primary and secondary $\mathrm{SCH}$ described in the literature with the aim to recollect data from different case-reports and case-series, trying to summarize general aspects of this very rare disease, giving to pathologist, orthopedic surgeon and radiologist useful information. We analyzed general data, clinical 
aspects, treatment, histology and follow-up, focusing on the diagnostic aspects, which remain a dilemma for orthopedic surgeon, radiologist and pathologist. In fact, to date, despite of Bertoni's criteria (2) have an important diagnostic role, no reliable clinical and imaging signs of malignant transformation of SC into SCH are indicated (4).

\section{Methods}

We performed a wide search in PubMed prior to December 2015, using the key words "synovial chondrosarcoma", "synovial tumors" and "synovial malignant transformation". We also screened the references of the searched articles for additional information. The language of the included articles was restricted to English and French. We collected 42 abstracts in the form of case series and case reports, which reported 67 cases of primary or secondary SCH. Full texts of the articles were collected from different electronic and paper archives. Studies were taken into account only if they proved a histological diagnosis of $\mathrm{SCH}$, either primary or secondary, with or without evidence of pre-existing SC. Patients' information including age, sex, location of the tumor, duration of symptoms, treatments for SC, histological grade of CHS (when specified), treatments for $\mathrm{SCH}$, local recurrence, metastasis and eventual outcome were all extracted from resources and summarized in Table 1. As the articles were reported from various clinical departments (e.g., Orthopedics, Radiology, Pathology), different aspects of the disease were reviewed focusing on the diagnostic aspects, which remain a dilemma for orthopedic surgeon, radiologist and pathologist.

\section{Results}

The average age of $\mathrm{SCH}$ diagnosis was 56.9 years, with prevalence for male sex ( 37 males and 23 females, with odds/ratio male female of 1.6). In 7 cases gender was not reported. The average time to develop SCH from SC was 11.2 years. The most affected joint was the knee (47.7\%), followed by hip $(34.3 \%)$, ankle (5.9\%), shoulder (2.9\%), elbow (2.9\%), temporo-mandibular joint (2.9\%), wrist (1.4\%) and thumb (1.4\%). SCH was described as de novo sarcoma only in 13 cases (19\%) and consequently was secondary to SC in the rest of 45 cases (67.1\%). In 9 cases etiology could not be proven due to the lack of information of the papers.

We divided treatments in two categories: treatments for SC and for SCH. Thirty-eight patients received synoviectomies for SC, including arthroscopic synoviectomy. More than one synoviectomy was performed in 18 cases. Only 18 patients underwent biopsies (incisional or needle biopsy) as first treatment. Five patients underwent intralesional excision as first treatment. Three cases were first approached with marginal excisions. Fourteen patients underwent total joint replacement (usually associated with total or subtotal synoviectomy) of which 9 were total hip replacement (THR), 3 were total knee replacement (TKR) and 2 were total elbow replacement.

When histological diagnosis was specified, grade 2 CHS was the most frequent histotype (22 cases), followed by grade 1 CHS (7 cases) and grade 3 CHS (7 cases). The other cases were reported as CHS without histological grading.

Regarding treatment for $\mathrm{SCH}$, only 14 patients underwent limb-salvage surgery. Amputations were performed in 40 patients (59.7\%). Five patients refused hemipelvectomy and in 5 cases treatment was not reported. Two patients were treated with debulking surgery and one case was followed over time after marginal excision. Nineteen patients had local recurrence $(28.3 \%)$. In 14 patients local status after treatment for SCH was not available. Nineteen patients developed metastases (28.3\%), all localized to the lungs except in one case in which metastasis were localized to the scalp. Although adjuvant therapies are not indicated in CHS, we reported 6 cases of palliative radiotherapy, 4 cases of chemotherapy for metastatic disease and 2 cases of multimodal therapies for metastatic disease. At last followup, 34 patients had no evidence of disease (NED), 14 were dead of disease (DOD), 4 were alive with disease (AWD), and 6 were lost. In 9 cases outcomes were not reported. When there was a match between histological grade of malignancy and outcome, we reported that among grade $3 \mathrm{SCH}, 3$ patients were DOD, 1 was AWD and only 3 patients had NED. Among grade 2 CHS, 6 patients were DOD, 14 had NED and 1 was AWD. Among grade 1 CHS, 3 patients had NED, 1 was DOD and 1 was lost. When there was a match between site of disease and outcome, survivals were similar. In fact, when the disease was localized to the knee, 15 patients (46.8\%) had NED and 6 (18.7\%) were DOD. When the disease was localized to the hip, 11 patients (47.8\%) had NED and 7 (30\%) were DOD.

\section{Conclusions}

$\mathrm{SC}$ is a rare benign disorder originating from the synovium, as result of self-limiting proliferative and metaplastic 


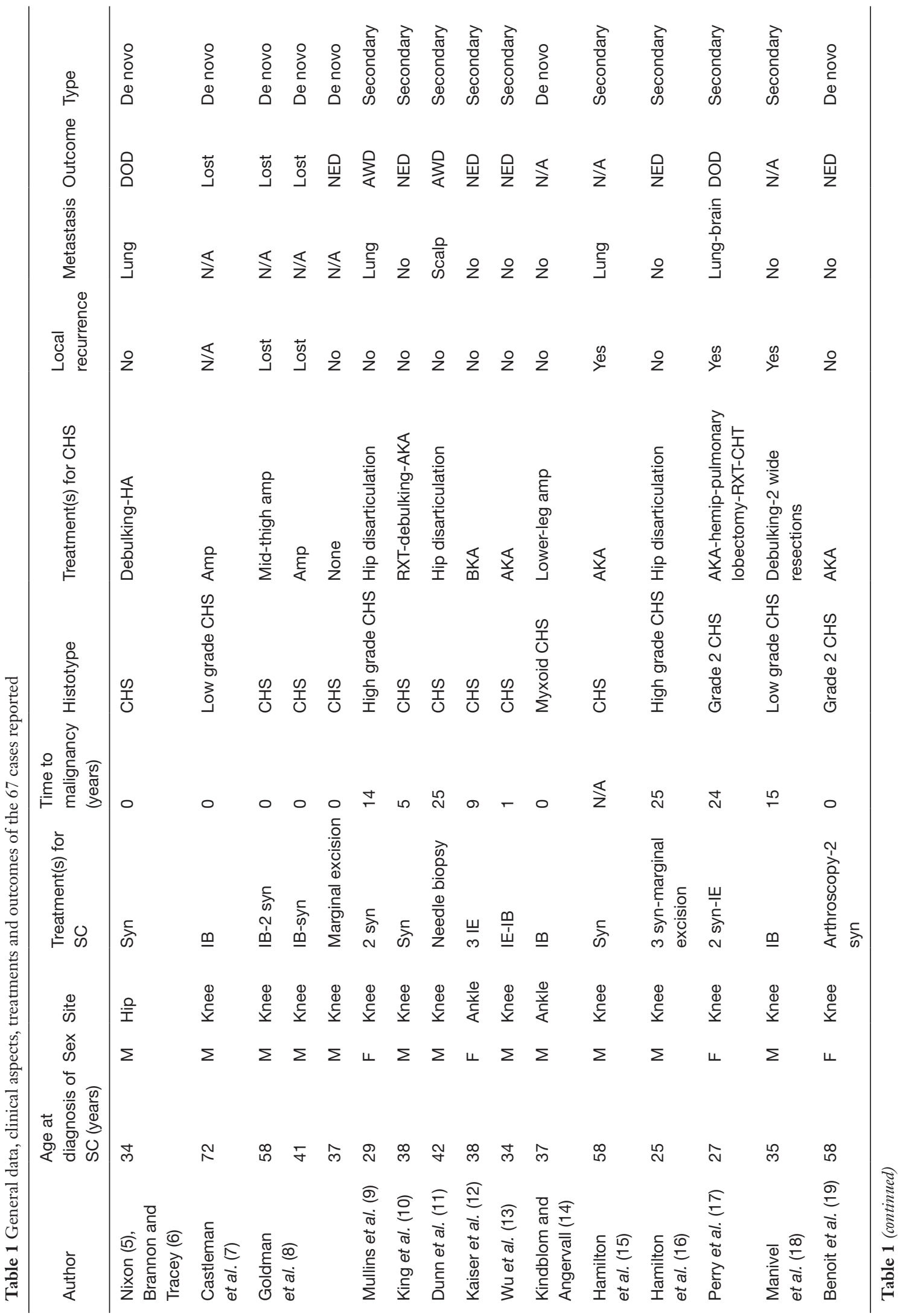




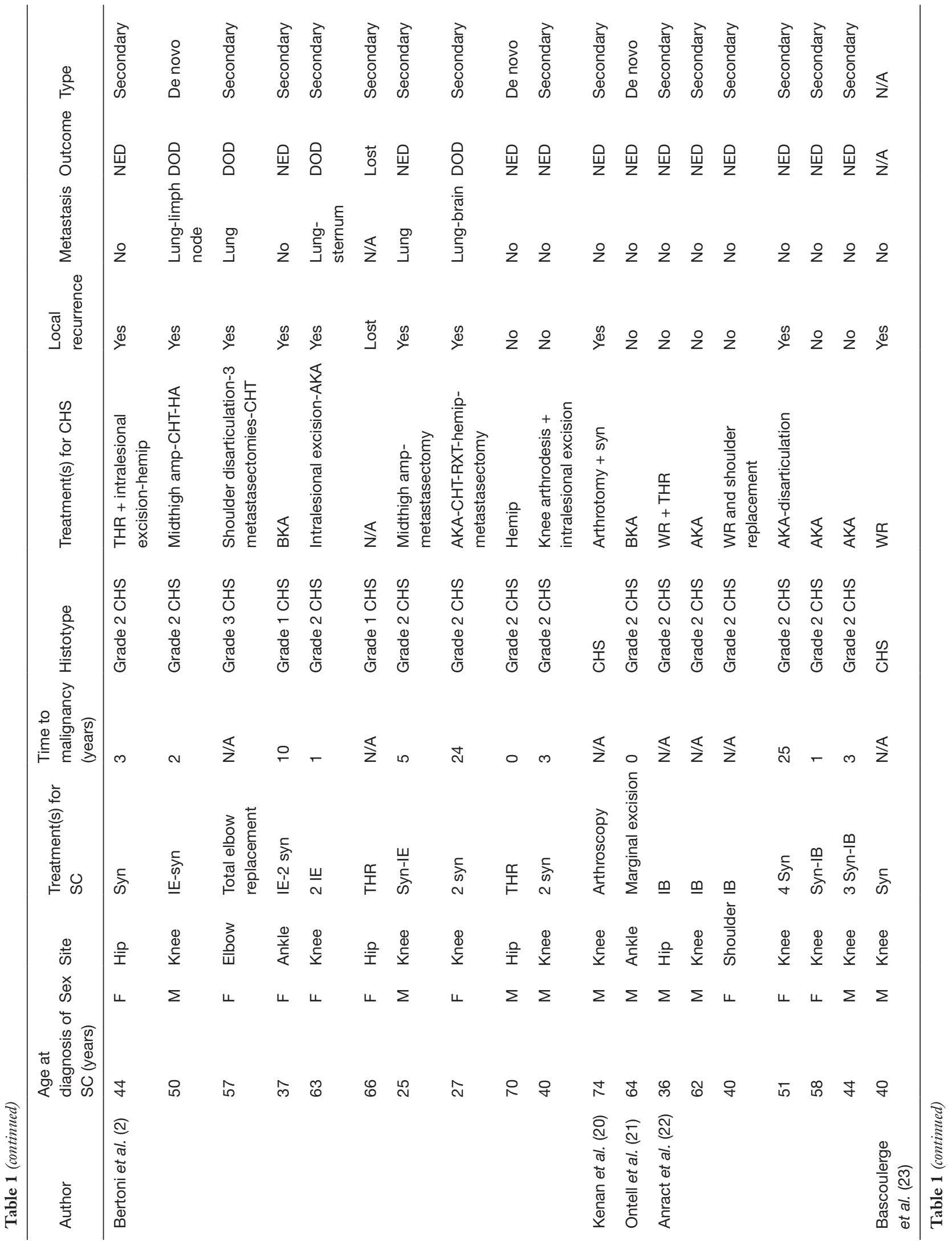




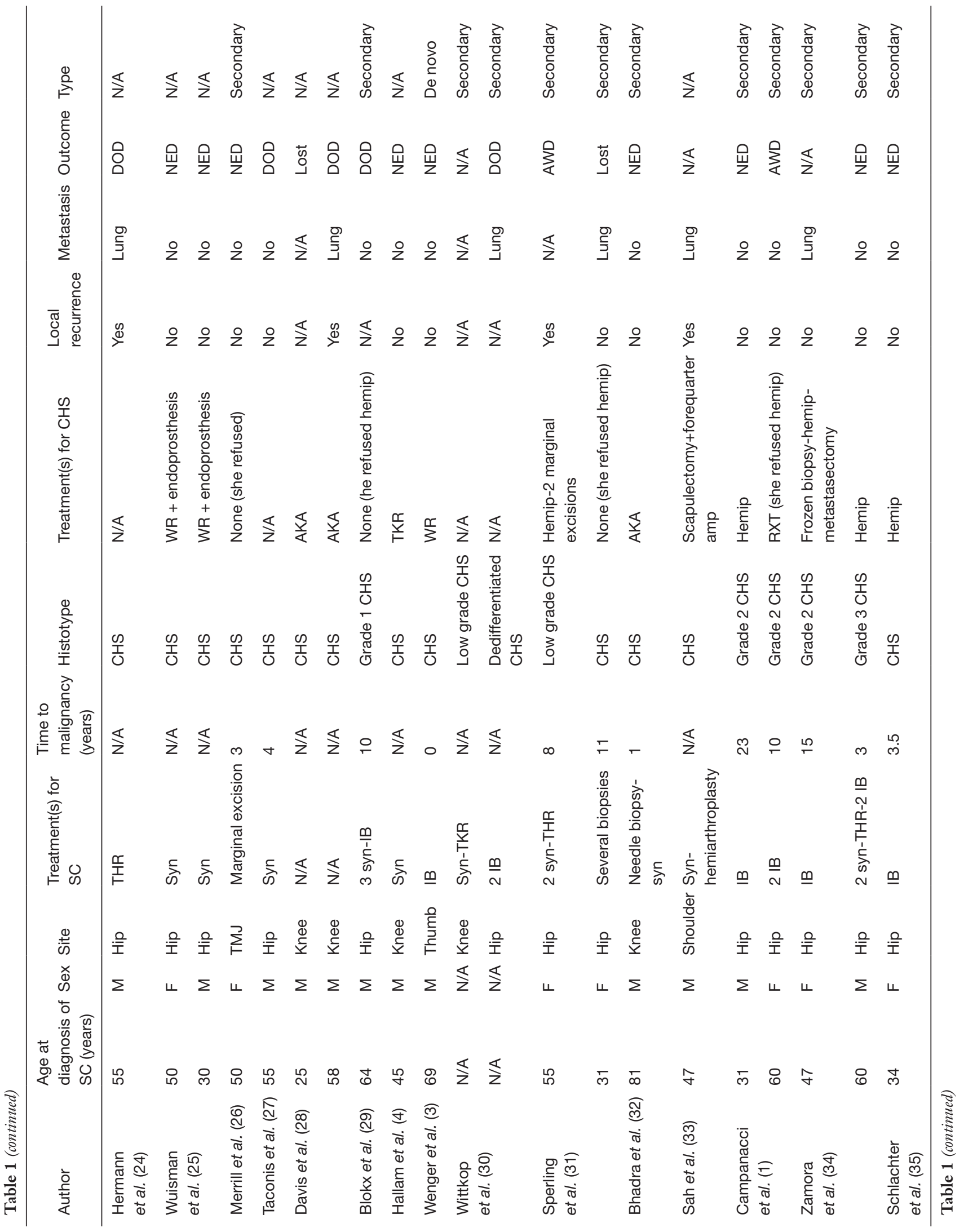




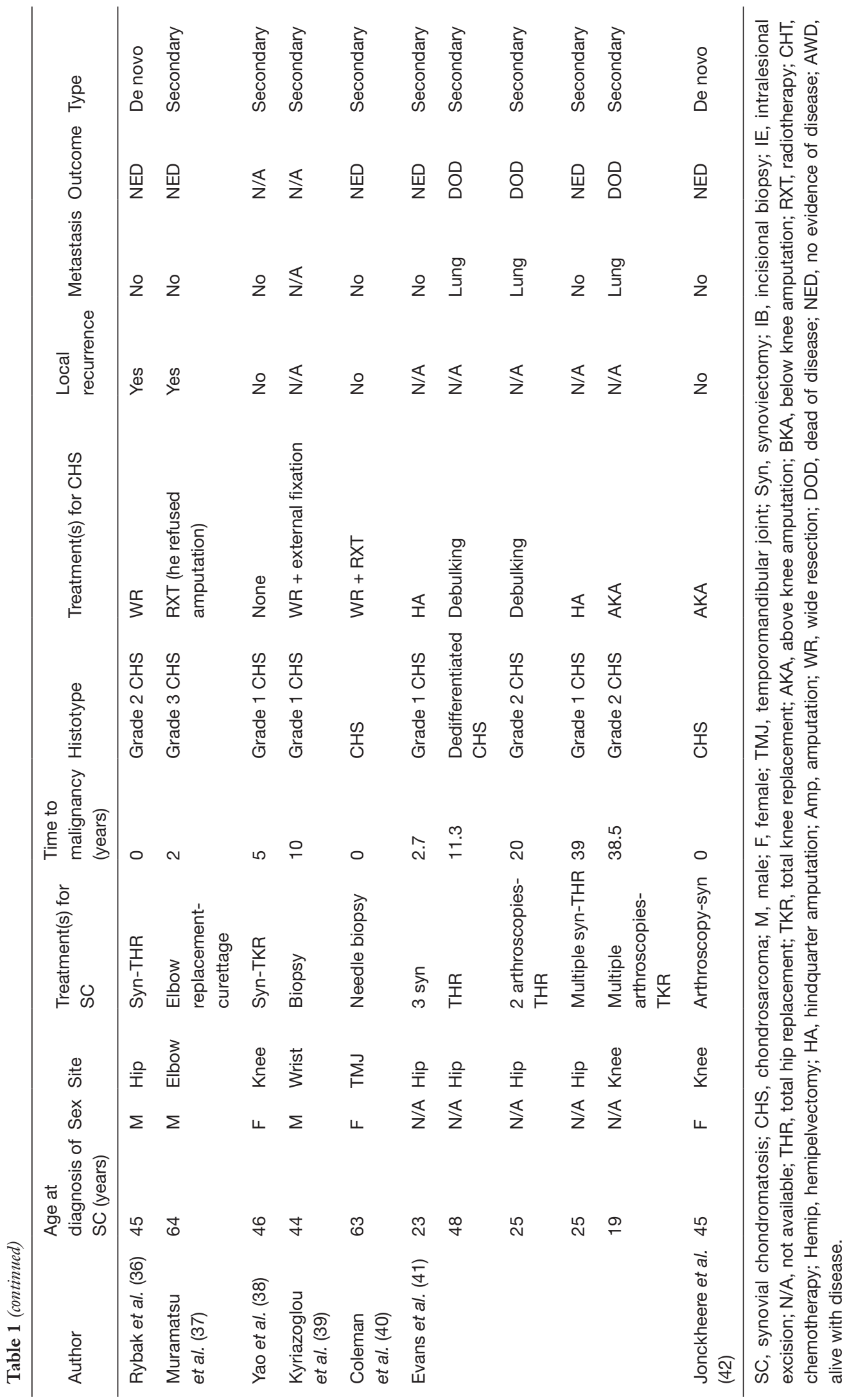


changes in the synovial membrane of the joints, tendon sheaths, or bursae, leading to formation of intrasynovial cartilaginous nodules (43). The disease was first described by Leannac in 1813; however, its current description was not applied until 1958 by Jaffe (44). Two types of SC have been described (45): in primary SC the metaplasia takes place within the synovial membrane and the cartilage nodules later detach from the synovium forming loose bodies in the joint cavity; in secondary SC the cartilage nodules may develop in the presence of intra-articular cartilage loosened bodies. In primary SC the histological pattern is characterized by nodules with irregular cellularity and focal atypia of chondrocytes. The secondary form, characterized by reactive cartilaginous nodules and indolent course, is most related to degenerative joint disease, osteochondritis dissecans, rheumatoid arthritis and trauma (1).

The exact prevalence of SC is unknown but it usually affects the third to fifth decades of life (46), with men being affected two to four times more frequently than women (47). The knee is the most commonly affected large joint followed by hip, shoulder, elbow, ankle and wrist (24). Patient' clinical symptoms typically include pain, swelling and restricted joint movement (48). The symptoms are often insidious at disease onset and are gradually progressive, although rare spontaneous regression has been reported (49).

The most widely quoted classification for SC is by Milgram and combines radiographic and histopathological features to describe three types of disease: the first, type 1 or early stage, where there are synovial-based masses without intra-articular loose bodies; the second, type 2 or intermediate stage, where there are synovial-based masses and free intra-articular loose bodies; and finally the third, type 3 or late stage, with multiple free osteochondral loose bodies without demonstrable synovial disease (50). In a recent case series of $20 \mathrm{SCs}$, the most frequent was type 1 (65\%), followed by type 2 (25\%) and type 3 (10\%) (30).

Radiological findings of SC are variable depending upon the level of calcification of the cartilaginous nodules, but in most cases imaging is fairly diagnostic (43). Radiographs, computed tomography (CT) and magnetic resonance imaging (MRI) show evidence of an intra-articular soft tissue mass with multiple mineralized osteocartilaginous nodules constituting the lesion and well-defined bone erosions on both sides of the joint (51). In non-mineralized lesions the MRI displays an intra-articular conglomerate mass isointense relative to muscle on T1-weighted images and hyperintense on T2-weighted images. In lesions with calcified cartilaginous nodules small areas of low signal- intensity are observed on a pulse sequence (52). From a histological point of view, SC demonstrates coalescent and well circumscribed hypercellular lobules of hyaline cartilage attached to the synovium. Typically, the cartilage cells are arranged in clustered patterns. In most cases the lesions show high hypercellularity and nuclear atypia. Myxoid change is rare and when present it is only focal; necrosis is absent $(43,51)$. The treatment often involves removal of loose bodies and subtotal synoviectomy, with or without joint replacement. Local recurrence is possible after incomplete synoviectomy, inadequate removal of loose bodies or diseased synovium at the time of initial surgery $(28,32,43)$ and it is estimated to be $23 \%(53)$.

Primary SC has a higher tendency to malignant transformation into SCH than secondary SC (2). This risk ranges from $1 \%$ to $5 \%$ according different case series $(28,36,53)$. As the clinical and radiological features are very similar between SC and SCH, their differentiation is often difficult and represents a diagnostic problem for orthopedic surgeon, radiologist and pathologist. Because of the differences in treatment and prognosis between the two pathologies, attempts have been made to identify features that might aid in differentiating the two entities (36). However, many authors have found significant overlap with no definitive clinical or radiologic criteria of malignancy that can be used to distinguish SC from SCH $(2,27,30,34,53)$. Clinically, both may present with pain, swelling and restricted movement of the affected joint with longstanding symptoms. Several authors speculate that a rapid deterioration of a longstanding clinical history or rapid recurrence after synoviectomy may indicate malignant transformation $(31,34,53)$.

From a radiological point of view a permeated and destructive pattern rather than an erosive one is suspicious for malignancy (25). In contrast, Wittkop et al. did not observe any MRI features to distinguish the malignant changes of a SC (30).

Several authors have tried to identify reliable diagnostic criteria. In 1991, Bertoni et al. indicated the histopathological features to differentiate SC from SCH (2). In their opinion, the cartilage cells, arranged in clusters in SC, tended to arrange in sheets without clustering effect in SCH. In SCH there was an evident myxoid change in the matrix and hypercellularity with round and spindle cell appearance. In addition, areas of necrosis were seen in $\mathrm{SCH}$, which were a sign of malignancy. At the interface between tumor and healthy bone, SC was seen to erode the bone with "pushing margins", while the SCH had a permeated behavior with 
typical "filling-up" of marrow spaces. In 1996, Anract et al. (22) sustained that three conditions have to be respect to demonstrate the malignant transformation of a SC: a pre-existing SC proven histologically; actual CHS proven histologically; coexistence of both areas of SC and CHS in the resected specimen. They also indicated that the only MRI criterion of malignancy was the invasion of the bone medullar canal. More recently, in 2003, Sperling et al. (31) speculated that the under-expression of the BCL-2 (a cell survival marker) in $\mathrm{SCH}$ could be used as diagnostic immunohistochemical tool. Moreover, cytogenetic data can offer important information for the diagnosis and our understanding of the development of SCH from SC. In 2013, Kyriazoglou et al. (39) performed a cytogenetic analysis of a secondary SCH in a 54-year-old man, finding a novel chromosomal translocation between chromosome 1 and 14 .

From our systematic literature review, we can assess that SCH is a very rare disease, with only 67 cases reported in the literature. We were able to document all cases. In the majority of them $(67.1 \%)$ the disease was secondary to malignant transformation of a pre-existing SC, with an average time to malignancy of 11.2 years. No etiological factors can be indicated, even though in some cases there is a history of trauma. No familiar cases were reported. Surgery ended up with amputation in $59.7 \%$ of cases. Local recurrence rate was $28.3 \%$. Taking into consideration that most of cases were grade $2 \mathrm{CHS}$, these data are not acceptable and not comparable to those of conventional CHS.

We concluded that prognosis of $\mathrm{SCH}$ is worse than conventional CHS and we speculated this is due to the difficult site of the tumor (intra-articular), diagnostic delay and subsequent inappropriate previous treatments. An important limit of this study is that some papers do not report complete information and some cases are reported as CHS without histological grade.

To date, no reliable clinical and imaging signs of malignant transformation of SC into SCH are indicated. We consider diagnosis difficult and often achieved with important delay. Average time to malignancy is 11.2 years and it can be considered not only as part of the natural history of the disease, even as diagnostic delay, because we do not exclude that the tumor could be a SCH from the onset. Diagnosis is possible only with the cooperation of orthopedic surgeon, radiologist and pathologist and can be achieved evaluating clinical aspects, radiological findings and histopathological features case by case. We consider that a rapid deterioration of a longstanding disease or rapid recurrence after synoviectomy should be considered suspicious of malignancy and should be treated at, or referred to, a tertiary hospital familiar with managing these often complex tumors. Since most amputations were done for recurrence after inappropriate surgery, wide resection margins achieved at primary surgical procedure might improve the limb salvage rate in these patients.

\section{Acknowledgements}

None.

\section{Footnote}

Conflicts of Interest: The authors have no conflicts of interest to declare.

\section{References}

1. Campanacci DA, Matera D, Franchi A, et al. Synovial chondrosarcoma of the hip: report of two cases and literature review. Chir Organi Mov 2008;92:139-44.

2. Bertoni F, Unni KK, Beabout JW, et al. Chondrosarcomas of the synovium. Cancer 1991;67:155-62.

3. Wenger DE, Sundaram M, Unni KK, et al. Acral synovial chondrosarcoma. Skeletal Radiol 2002;31:125-9.

4. Hallam P, Ashwood N, Cobb J, et al. Malignant transformation in synovial chondromatosis of the knee? Knee 2001;8:239-42.

5. Nixon JE, Frank GR, Chambers G. Synovial osteochondromatosis with report of four cases, one showing malignant change. U S Armed Forces Med J 1960;11:1434-45.

6. Brannon EW, Tracey JF. Hindquarter amputation for hip chondrosarcoma. U S Armed Forces Med J 1957;8:1517-26.

7. Castleman B. Case Records of the Massachusetts General Hospital. Weekly clinicopathological exercises. Case 231962. N Engl J Med 1962;266:725-9.

8. Goldman RL, Lichtenstein L. Synovial Chondrosarcoma. Cancer 1964;17:1233-40.

9. Mullins F, Berard CW, Eisenberg SH. Chondrosarcoma Following Synovial Chondromatosis. A case study. Cancer 1965;18:1180-8.

10. King JW, Spjut HJ, Fechner RE, et al. Synovial chondrosarcoma of the knee joint. J Bone Joint Surg Am 1967;49:1389-96.

11. Dunn EJ, McGavran MH, Nelson P, et al. Synovial chondrosarcoma. Report of a case. J Bone Joint Surg Am 1974;56:811-3. 
12. Kaiser TE, Ivins JC, Unni KK. Malignant transformation of extra-articular synovial chondromatosis: report of a case. Skeletal Radiol 1980;5:223-6.

13. Wu KK, Guise ER. Synovial chondrosarcoma: a case report. Orthopedics 1981;4:291-4.

14. Kindblom LG, Angervall L. Myxoid chondrosarcoma of the synovial tissue. A clinicopathologic, histochemical, and ultrastructural analysis. Cancer 1983;52:1886-95.

15. Hamilton A, Davis RI, Nixon JR. Synovial chondrosarcoma complicating synovial chondromatosis. Report of a case and review of the literature. J Bone Joint Surg Am 1987;69:1084-8.

16. Hamilton A, Davis RI, Hayes D, et al. Chondrosarcoma developing in synovial chondromatosis. A case report. J Bone Joint Surg Br 1987;69:137-40.

17. Perry BE, McQueen DA, Lin JJ. Synovial chondromatosis with malignant degeneration to chondrosarcoma. Report of a case. J Bone Joint Surg Am 1988;70:1259-61.

18. Manivel JC, Dehner LP, Thompson R. Case report 460: Synovial chondrosarcoma of left knee. Skeletal Radiol 1988;17:66-71.

19. Benoit J, Arnaud E, Moulucou A, et al. Synovial osteochondromatosis of the knee and synovial chondrosarcoma. Report of 2 cases. Rev Chir Orthop Reparatrice Appar Mot 1990;76:198-203.

20. Kenan S, Abdelwahab IF, Klein MJ, et al. Case report 817: Synovial chondrosarcoma secondary to synovial chondromatosis. Skeletal Radiol 1993;22:623-6.

21. Ontell F, Greenspan A. Chondrosarcoma complicating synovial chondromatosis: findings with magnetic resonance imaging. Can Assoc Radiol J 1994;45:318-23.

22. Anract P, Katabi M, Forest M, et al. Synovial chondromatosis and chondrosarcoma. A study of the relationship between these two diseases. Rev Chir Orthop Reparatrice Appar Mot 1996;82:216-24.

23. Bascoulergue G, Gougeon F, Lecomte-Houcke M, et al. Malignant synovial "chondromatosis" or chondrosarcomatous transformation of synovial chondromatosis of the knee?. Bull Cancer 1996;83:951-6.

24. Hermann G, Klein MJ, Abdelwahab IF, et al. Synovial chondrosarcoma arising in synovial chondromatosis of the right hip. Skeletal Radiol 1997;26:366-9.

25. Wuisman PI, Noorda RJ, Jutte PC. Chondrosarcoma secondary to synovial chondromatosis. Report of two cases and a review of the literature. Arch Orthop Trauma Surg 1997;116:307-11.

26. Merrill RG, Yih WY, Shamloo J. Synovial chondrosarcoma of the temporomandibular joint: a case report. J Oral
Maxillofac Surg 1997;55:1312-6.

27. Taconis WK, van der Heul RO, Taminiau AM. Synovial chondrosarcoma: report of a case and review of the literature. Skeletal Radiol 1997;26:682-5.

28. Davis RI, Hamilton A, Biggart JD. Primary synovial chondromatosis: a clinicopathologic review and assessment of malignant potential. Hum Pathol 1998;29:683-8.

29. Blokx WA, Rasing LA, Veth RP, et al. Late malignant transformation of biopsy proven benign synovial chondromatosis: an unexpected pitfall. Histopathology 2000;36:564-6.

30. Wittkop B, Davies AM, Mangham DC. Primary synovial chondromatosis and synovial chondrosarcoma: a pictorial review. Eur Radiol 2002;12:2112-9.

31. Sperling BL, Angel S, Stoneham G, et al. Synovial chondromatosis and chondrosarcoma: a diagnostic dilemma. Sarcoma 2003;7:69-73.

32. Bhadra AK, Pollock R, Tirabosco RP, et al. Primary tumours of the synovium. A report of four cases of malignant tumour. J Bone Joint Surg Br 2007;89:1504-8.

33. Sah AP, Geller DS, Mankin HJ, et al. Malignant transformation of synovial chondromatosis of the shoulder to chondrosarcoma. A case report. J Bone Joint Surg Am 2007;89:1321-8.

34. Zamora EE, Mansor A, Vanel D, et al. Synovial chondrosarcoma: report of two cases and literature review. Eur J Radiol 2009;72:38-43.

35. Schlachter TR, Wu Q, Matlyuk-Urman Z. AIRP best cases in radiologic-pathologic correlation: synovial chondrosarcoma. Radiographics 2011;31:1883-8.

36. Rybak LD, Khaldi L, Wittig J, et al. Primary synovial chondrosarcoma of the hip joint in a 45-year-old male: case report and literature review. Skeletal Radiol 2011;40:1375-81.

37. Muramatsu K, Miyoshi T, Moriya A, et al. Extremely rare synovial chondrosarcoma arising from the elbow joint: case report and review of the literature. J Shoulder Elbow Surg 2012;21:e7-11.

38. Yao MS, Chang CM, Chen CL, et al. Synovial chondrosarcoma arising from synovial chondromatosis of the knee. JBR-BTR 2012;95:360-2.

39. Kyriazoglou AI, Rizou H, Dimitriadis E, et al. Cytogenetic analysis of a low-grade secondary peripheral chondrosarcoma arising in synovial chondromatosis. In Vivo 2013;27:57-60.

40. Coleman H, Chandraratnam E, Morgan G, et al. Synovial chondrosarcoma arising in synovial chondromatosis of the temporomandibular joint. Head Neck Pathol 2013;7:304-9. 


\section{Page 10 of 10}

41. Evans S, Boffano M, Chaudhry S, et al. Synovial chondrosarcoma arising in synovial chondromatosis. Sarcoma 2014;2014:647939.

42. Jonckheere J, Shahabpour M, Willekens I, et al. Rapid malignant transformation of primary synovial chondromatosis into chondrosarcoma. JBR-BTR 2014;97:303-7.

43. Campanacci M, editor. Bone and soft tissue tumors. 2nd ed. New York: Springer, 1999.

44. Jaffe HL, editor. Tumours and Tumourous Conditions of the Bones and Joints, Kimpton, London, UK, 1958.

45. Villacin AB, Brigham LN, Bullough PG. Primary and secondary synovial chondrometaplasia: histopathologic and clinicoradiologic differences. Hum Pathol 1979;10:439-51.

46. Mankin HJ. Synovial Chondromatosis. In: Mankin HJ, editor. Pathophysiology of Orthopaedic Disease. Rosemont: The American Academy of Orthopaedic Surgeon, 2006:53-8.

Cite this article as: Biazzo A, Confalonieri N. Synovial chondrosarcoma. Ann Transl Med 2016;4(15):280. doi: 10.21037/ atm.2016.06.23

\section{Biazzo and Confalonieri. Synovial chondrosarcoma revisited.}

47. Darfam MD, Czerniak B. Synovial Lesions. In: Bone Tumours. Mosby, St. Louis, Mo, USA: 1998:1041-86.

48. Murphy FP, Dahlin DC, Sullivan CR. Articular Synovial Chondromatosis. J Bone Joint Surg Am 1962;44:77-86.

49. Butt SH, Muthukumar T, Cassar-Pullicino VN, et al. Primary synovial osteochondromatosis presenting as constrictive capsulitis. Skeletal Radiol 2005;34:707-13.

50. Milgram JW. Synovial osteochondromatosis: a histopathological study of thirty cases. J Bone Joint Surg Am 1977;59:792-801.

51. Kransdorf MJ, Meis JM. From the archives of the AFIP. Extraskeletal osseous and cartilaginous tumors of the extremities. Radiographics 1993;13:853-84.

52. Sheldon PJ, Forrester DM, Learch TJ. Imaging of intraarticular masses. Radiographics 2005;25:105-19.

53. Murphey MD, Vidal JA, Fanburg-Smith JC, et al. Imaging of synovial chondromatosis with radiologic-pathologic correlation. Radiographics 2007;27:1465-88. 